Relations industrielles

Industrial Relations

\title{
Jugements récents
}

\section{Pierre Verge}

Volume 25, numéro 2, 1970

URI : https://id.erudit.org/iderudit/028135ar

DOI : https://doi.org/10.7202/028135ar

Aller au sommaire du numéro

\section{Éditeur(s)}

Département des relations industrielles de l'Université Laval

\section{ISSN}

0034-379X (imprimé)

1703-8138 (numérique)

Découvrir la revue

Citer cet article

Verge, P. (1970). Jugements récents. Relations industrielles / Industrial Relations, 25(2), 376-378. https://doi.org/10.7202/028135ar

Tous droits réservés (C) Département des relations industrielles de l'Université Laval, 1970
Ce document est protégé par la loi sur le droit d'auteur. L’utilisation des services d'Érudit (y compris la reproduction) est assujettie à sa politique d'utilisation que vous pouvez consulter en ligne.

https://apropos.erudit.org/fr/usagers/politique-dutilisation/ 


\title{
JUGEMENTS RÉCENTS
}

\author{
Pierre Verge
}

\section{SYNDICAT DES EMPLOYÉS DU TRANSPORT DE MONTREAL (C.S.N.)}

\section{c. PROCUREUR GÉNÉRAL DE LA PROVINCE DE QUÉBEC.}

Appel entendu le 6 mars 1969 par la Cour suprême du Canada; Jugement prononcé le 28 avril 1970; Motifs du jugement par M. le Juge Fauteux; souscrivent à son avis MM. les Juges Abbott, Marchand Hudson et Ritchie; motifs de dissidence par M. le Juge Pigeon; souscrit d son avis, M. le Juge Spence.

Appel d'un arrêt unanime de la Cour d'appel rejettant un appel à l'encontre d'une injonction émise selon l'article 99 du Code du Travail par le Juge en chef de la Cour supérieure. Appel rejetté.

Droit du travail - Procédure civile - Grève - Santé ou sécurité publique - Injonction - Absence d'avis - District de présentation de la requête - Applicabilité des règles du Code de procédure civile à l'injonction selon l'article 99 du Code du Travail.

Code du travail, S.R.Q., 1964, c. 141, a. 99, 4, n);

Code de procédure civile, (anc.), a. 957, parag. 3, a. 961, (nouv.) a. 5, 20, 753.

\section{LES FAITS}

Les salariés du transport en commun de la région de Montréal étaient en grève depuis près de trois semaines. Le lieutenant-gouverneur en conseil, étant d'avis que cette grève dans un «service public» mettait en danger la «santé ou la sécurité publique» constitua, selon l'article $99 \mathrm{du}$ Code du Travail une commission d'enquête chargée de constater les faits; le lendemain, le procureur-général demanda au juge en chef de la Cour supérieure de décerner une injonction pour mettre fin à la grève. Ce dernier, également d'avis que cet arrêt de travail «mettait en péril la santé ou la sécurité publique », fit droit à cette requête et accorda l'injonction pour la période prévue à l'article 99 , soit pendant les quatrevingt jours suivant celui de l'établissement de la commission d'enquête.

Cette injonction fut accordée sans que les intimés n'aient été appelés à exposer leurs vues, c'est-à-dire, sur la foi des déclarations assermentées au soutien de la requête. C'est précisément cette absence d'avis aux intimés, partant d'audition de ceux-ci, que visait essentiellement l'ordonnance d'injonction, selon les appelants. L'on a aussi plaidé que la requête du procureur-général aurait dû être présentée, 
non pas dans le district de Québec, mais dans celui de Montréal, lieu de la grève et du domicile des grévistes.

\section{OPINION DES JUGES}

La majorité des juges de la Cour suprême reprennent à leur compte les motifs retenus par la Cour d'appel, pour enteriner en quelque sorte, comme elle l'avait fait, la procédure suivie.

L'injonction dont il s'agit à l'article 99 du Code du travail est «autonome » par rapport au régime de l'injonction prévue du Code de procédure civile. Or, cette disposition particulière, compte tenu du caractère d'urgence de la procédure, ne prescrit aucune signification aux intimés de la requête d'injonction :

«Il est manifeste que les dispositions spéciales de l'article 99 du Code du Travail ont pour objet et unique objet de prévenir ou empêcher que la santé et la sécurité publiques soient mises en péril par une grève de salariés à l'emploi d'un service public. En décernant l'injonction qu'autorise cet article pour écarter ce danger, le juge de la Cour supérieure n'est pas appelé à déterminer un litige mû entre justiciables. Il n'a rien à voir au différend qui existe entre la Direction et les employés d'un service public, différend dont le déféré préalable à une commission d'enquête constituée par le lieutenant-gouverneur en conseil conditionne le droit du Procureur général de lui soumettre la requête et son droit d'exercer le pouvoir qui lui est conféré. Aussi bien, en émettant l'ordonnance prévue à ces dispositions spéciales pour provisoirement empêcher une grève appréhendée ou mettre fin à une grève en cours, le juge de la Cour supérieure ne fait que mettre en oeuvre le droit que sanctionne ces dispositions et que tous les membres de la collectivité sociale, - y compris la Direction et les salariés du service public concerné, - possèdent en commun, soit le droit d'être protégés contre la mise en péril de la santé et de la sécurité publiques.

Cette ordonnance provisoire constitue une mesure d'urgence. Pour être efficace et pour que soit atteint l'objet visé par la Législature, la mise en oeuvre de cette ordonnance doit se produire avec la plus grande célérité, soit qu'il s'agisse d'empêcher une grève appréhendée ou de mettre fin à une grève en cours. Le législature en a prescrit aucune signification de la requête du Procureur général; elle a laissé au juge de la Cour supérieure qui en est saisi, le pouvoir de « décerner toute injonction jugée appropriée pour empêcher cette grève ou y mettre fin ». Tout cela implique qu'il s'agit là d'une procédure sommaire et que l'exercice du pouvoir conféré au juge n'est pas obligatoirement assujetti aux délais incidents à la signification de la requête et autres délais afférents à une contestation éventuelle. »

(Notes, J. Fauteux, pp. 6 et 7.)

M. le juge Pigeon, minoritaire, en un premier temps, fait abstraction des règles du Code de procédure civile (sans présumer pour autant qu'elles ne sont pas appli- 
cables) et met de l'avant les arguments suivants se rattachant davantage à la situation dans laquelle furent véritablement placés les intimés :

- L'injonction émise n'avait pas un caractère intérimaire, mais interdisait la grève pour la durée totale prévue par la Loi ; la règle générale «audi alteram partem» s'imposait (notes, pp. 2 et 3 ).

- Il était factice de prétendre à l'existence d'une situation d'urgence pour contourner cet impératif : la grève, déjà en cours depuis trois semaines avait elle-même été précédée d'un préavis, selon l'article 99 . Il s'agit là, évidemment, d'une matière à appréciation. Un peu dans la même veine, cette observation à l'effet que c'est «... aux injonctions décernées sans avis que la désobéissance est fréquente chez nous dans les conflits ouvriers... 》 (notes, p. 4).

- Surtout, les grévistes, «faisaient la grève dans la légalité, usaient d'un droit. Or, l'injonction, en pratique, modifiait les «rapports des forces», dans cette confrontation qu'est la grève :

«Il ne faut pas oublier que, dans un cas comme celui qui nous concerne, l'on n'est pas en présence d'un arrêt de travail illégal ou d'un syndicat ouvrier qui a recours à la violence ou à d'autres illégalités. Ici, le tribunal saisi de la demande d'injonction était en face de syndicats faisant une grève dont la légalité n'était pas contestée et qui, par conséquent, usaient d'un droit. La requête du procureur général était rien moins qu'une demande d'expropriation de ce droit dans l'intérêt général, expropriation temporaire si l'on veut, mais expropriation quand même et d'autant plus importante qu'elle aurait pour effet de modifier sérieusement le rapport des forces économiques dont dépend l'issue de tout conflit de travail.

Il est bien vrai que c'est l'autorité publique qui sollicitait l'injonction, jugeant qu'elle était nécessaire et que les syndiqués du transport urbain de Montréal devaient, dans l'intérêt général, subir l'expropriation de leur droit de grève pendant près de trois mois. Mais le législateur n'a pas voulu que la décision du gouvernement soit définitive. Il a ordonné que l'injonction soit décernée seulement si le juge de la Cour supérieure 《est d'avis que la grève met en péril la santé ou la sécurité publique ». Permettre au juge saisi d'une telle requête de rendre une décision définitive sans entendre les représentants des grévistes est, à mon avis, donner à son rôle un caractère ministériel au lieu de celui d'arbitre impartial et éclairé qui doit être le sien.»

De façon subsidiaire, en un second temps, M. le juge Pigeon se situe dans le contexte de l'injonction selon le Code de procédure civile. (Il ne se prononce toutefois pas quant à leur applicabilité à l'injonction prévue à l'article 99 du Code du travail ; il s'y montre néanmoins favorable.)

Il nous place devant le dilemme suivant, à partir de l'article 753 du Code de procédure civile : s'il s'applique à l'espèce, l'injonction provisoire ne peut dépasser dix jours; sinon, simplement, le Code de procédure civile ne permet pas autrement l'injonction sans avis. 